\title{
Local Perceptions towards Tourism Impacts Related to Homestay Programme
}

\author{
Sharon Esther Donny Sita and Nor Ashikin Mohd Nor \\ School of Tourism, Hospitality and Environmental Management, COLGIS \\ Universiti Utara Malaysia \\ 06010, Sintok, Kedah Darul Aman, Malaysia
}

Tel: 60-4-928-8153_E-mail: sita_ms87@yahoo.com.my and norashikin@uum.edu.my

\author{
Sharon Esther Donny Sita (Corresponding author) \\ School of Tourism, Hospitality and Environmental Management, COLGIS \\ Universiti Utara Malaysia \\ 06010, Sintok, Kedah Darul Aman, Malaysia
}

Tel: 60-4-928-8153Ｅ-mail: sita_ms87@yahoo.com.my

Received: July 23, 2014 Accepted: October 29, 2014 Published: February 1, 2015

doi:10.5296/jmr.v7i2.6952 URL: http://dx.doi.org/10.5296/jmr.v7i2.6952

\begin{abstract}
The purpose of this research was to identify how degrees of contact derived from frequency of communication with tourists influence the local perceptions towards social impacts of tourism. This research also examines the local's support for additional tourism development or support for restrictions on tourism development in Kampung Benuk Homestay $(\mathrm{KBH})$, Kuching. Two theoretical frameworks, namely Social Exchange Theory and Model of Resident Tourism Perceptions and Attitudes were adapted in this research. A qualitative method was employed in which a semi-structured interview was conducted face-to-face with 12 respondents. Data from these interviews were analysed manually using Microsoft Word 2010. From the findings, three categories of respondent: 'High Contact' (HC), 'Medium Contact' (MC), and 'Low Contact' (LC), showed significantly different perceptions towards social impacts of homestay programme. The findings indicated that the positive or negative perceptions towards social impacts influence the local's support for additional tourism
\end{abstract}




\section{Macrothink}

development or support for restrictions on tourism development. The HC respondents were positive towards social impacts and supported additional tourism development. In contrast, the $\mathrm{MC}$ respondents perceived social impacts negatively, but agreed to support additional tourism development. The LC respondents had positive perceptions towards social impacts, but were both supportive for additional tourism development and for restrictions on tourism development. The research provides practical implications for local government and stakeholders for planning and policy in the community-based homestay programme in Sarawak. The theoretical implication highlights the need for heterogeneous respondents in the future homestay programme studies on perceptions towards social impacts of tourism.

Keywords: Homestay programme, Local residents' perceptions, Social impacts, Qualitative, Sarawak 


\section{Introduction}

In Malaysia, a homestay programme is one of the tourism initiatives by the government to encourage the local people to get involved with tourism activities. Given that this homestay programme is to encourage the villagers to involve in the programme, an equal distribution of the benefits from the programme among the villagers is mandatory (Ministry of Tourism and Culture, Malaysia, MOTAC, 2014). Besides helping the locals to generate income from selling handmade-handicraft products like bangles or basket made from rattan, homestay programme gives chance to the local people to interact with tourists from other countries during the homestay visits. These activities are in line with the notion of this programme to improve the locals' quality of life by encouraging them to communicate with the homestay tourists.

Number of studies that have focussed on local perceptions towards tourism social impacts has increased (Brunt \& Courtney, 1999; Hsu, 2006; Long, 2012). These previous studies found that the quality of life of locals at a tourist destination has always been associated with impacts of tourism. Relating to the perceived impacts, some groups of local residents were badly affected while others have not affected at all. Generally, most of the studies on perceived tourism impacts found that benefits are more obvious than the costs, and this finding was associated with the positive perceptions towards tourism.

In a context of a homestay programme, opinions from the homestay operators or other related entrepreneurs in developing the programme have been highlighted in many publications (Abdul Razzaq, Hadi, Mustafa, Hamzah, Khalifah \& Mohamad, 2011; Bhuiyan, Siwar \& Mohamad Ismail, 2013). Generally, their perceptions towards impacts of the homestay programme were to preserve the culture, improve the quality of life, and establish sustainable growth of tourism (Abdul Razzaq et al., 2011; Bhuiyan et al., 2013). However, these authors were not able to explain why the different groups of residents have different perceptions towards tourism impacts occurred given that the study did not group the residents. The reality that local people are not a homogeneous group and their different perceptions derived from frequency of communication with tourists must be acknowledged. A lack in doing so provides evidence for the observation made by Brunt and Courtney (1999) that findings from the past studies were too general since the homogeneity within the local residents was assumed in an aspect of perceiving the tourism impacts. Brunt and Courtney (1999) further affirmed that diverse perceptions can be better understood if the local people are viewed as a heterogeneous group despite living in a small community. Thus, the study to examine perceptions from the local people by grouping them into different categories is crucial for a better understanding on perceptions. The local people comprise of various vocations that associate with the different degrees of contact with tourists resulting to the local positive perception or negative perception. This could as well mean that locals either benefit from tourism or are negatively impacted by the tourism development.

Thus, the purpose of this research was to identify how degrees of contact derived from frequency of communication with tourists influence the local perceptions of social impacts of tourism as well as their support for additional tourism development or support for restrictions 
on tourism development in Kampung Benuk Homestay (KBH). The specific objectives of the research were 1) to examine how perceptions of social impacts of tourism differ depending on certain degrees of contact derived from frequency of communication with tourists in $\mathrm{KBH}$, and 2) to analyse whether local people support additional tourism development or support restrictions on tourism development based on their perceptions towards social impacts of tourism in $\mathrm{KBH}$.

\section{Literature Review}

\subsection{Tourism Impacts as Perceived by Local People}

Research about local residents' perceptions towards tourism impacts has increased. A number of recent authors focused on tourism impacts as perceived by local residents, and they found that the local residents perceive the social impacts positively if they accept the changes in tourism (Hsu, 2006; Long, 2012; Zhou, Lu \& Yoo, 2013). Among social benefits were identified, such as employment opportunities, diversification of activities and entertainment, and opportunity to meet new people. Several social costs associated with tourism activities were found, for example alcohol and drug abuse, crime, and traffic congestion. These findings provide evidence for earlier studies that the changes in tourism have resulted in both positive and negative social impacts (Brunt \& Courtney, 1999).

In an article written by Ap (1992) titled Residents' Perceptions on Tourism Impacts, a well-known and suitable framework to analyse the local residents' perceptions of tourism impacts, that is a Social Exchange Theory (SET) was introduced. This SET has begun to be adopted by many authors of tourism impacts (Zhou et al., 2013). Since the SET involves the "exchange of resources between individuals and groups in an interactive situation" (Ap, 1992, p.668), the findings from previous studies revealed that the local residents who perceived they would benefit from tourism activities were likely to agree with positive tourism impacts. However, a finding from a study by Horn, Simmons, and Fairweather (2000) found that local resident were positive towards the future tourism development in their area, although tourism has impacted them negatively. Their finding showed that while tourism impacted the local residents negatively, they were not feared that tourism would affect their quality of life negatively. This is supported by an observation by Zhou et al., (2013) in their study to investigate residents' perceived impacts of the gaming tourism development in Macau. Zhou et al., (2013) were concerned with the attitudes among the residents in Macau towards gaming impacts given that they still supportive of gaming development even though they did not receive any benefits from the gaming industry.

Support towards development of tourism industry can be determined by investigating the tourism impacts perceived by the local residents, specifically by identifying the benefits and costs resulting from the tourism industry (Zhou et al., 2013). To see this connection in a context of a homestay programme, this research has also aimed to analyse whether local people support additional tourism development or support restrictions on tourism development based on their perceptions towards social impacts of tourism in KBH. Thus, to better understand the local residents' perceptions towards the impacts resulting from the homestay programme, a Model of Resident Tourism Perceptions and Attitudes by Perdue et 
al., (1990) was also adopted. The model developed by Perdue et al., (1990) asserts that locals who show support for additional tourism development are likely to perceive tourism impacts in the area positively. This model also suggests that locals who support additional tourism development are those who receive more benefits than costs from tourism activities. Furthermore, the model states that when local people support restrictions on tourism development, they are not likely to be supportive of future tourism development in their area.

\subsection{Local Residents’ Perceptions towards Tourism Impacts Based on Degrees of Contact}

Numerous researchers categorised the local residents into several groups. Horn et al., (2000) discovered that local residents who were highly involved in tourism prone to be more responsible in settling issues or problems faced by the villagers. Nevertheless, this group of local was positive towards tourism and appreciated the job opportunities offered to them. With that, several previous researchers found that individuals who were working in a tourism industry tend to be more supportive toward, and positive about tourism impacts compared to those who are not (Ap, 1992; Brunt \& Courtney, 1999). In this research, this type of respondent is referred to as High Contact category (HC).

Other than those who worked directly for the tourism industry, there were local residents who run other businesses, such as grocery businesses. This type of respondents was not depending entirely on tourism. Brunt and Courtney (1999) observe that this type of respondent in which in their study referred as the Low Contact category did not communicate with tourists as often as those who involved directly in the tourism activities. Given that they were not obviously affected from the development of tourism activities, tourism was not associated with their life quality. However, they acknowledged the purpose of tourist arrivals to their area. In this research, this group is referred as Medium Contact category (MC). The last group of respondent for this research referred as Low Contact category (LC) who had a low frequency of communication with tourists. A number of factors such as a health issue or perhaps not interested in helping to run the programme resulted in the categorization of these older adults as the low contact category (LC). Brunt and Courtney (1999) in their study found that the local residents who were the pensioners or older adults had variety of perceptions be it approvals or rejections towards tourism development in their area.

\section{Methods}

To obtain relevant and rich data for this research, a qualitative method was employed. It is a suitable method to understand the local perceptions since it looks "in depth at single communities" (Horn et al., 2000, p. 2). A semi-structured interview was employed to obtain a richer data on local perceptions towards tourism impacts. From these data, the researcher could determine the extent of the local support for additional tourism development or support for restrictions on tourism development. A snowball sampling was selected for this research. The first respondent to be interviewed was selected from the name listed in the directory for the registered homestays in Sarawak. After the interview with the first respondent completed, he or she was asked to nominate the next potential individual who was either in the same category of contact or from the other two categories. Only one respondent 
interviewed at one time. Note-taking was also employed to check for consistency with the tape-recorded interviews.

The interview questions comprised of three sections. Section One comprised of three questions addressed the local perceptions towards social impacts of tourism in KBH. These questions were asked to achieve the first objective of this research. Section Two was to determine the local's support for additional tourism development or support for restrictions on tourism development. Five questions were asked to achieve the second objective of this research. Section Three consisted of two questions to examine the future of tourism development in KBH. During the interview, the researcher communicated in Bahasa Melayu Sarawak given that the respondents could not communicate fluently in English language. Interviews were then transcribed and translated into English.

A total of 12 respondents were face-to-face interviewed in Kampung Benuk. Among the respondents, four villagers were interviewed from each category for degree of contact - High Contact (HC), Medium Contact (MC), and Low Contact (LC). Respondents who communicated more often with tourists in $\mathrm{KBH}$ were categorised in the $\mathrm{HC}$ category. There were homestay operators and villagers who worked directly for the homestay programme. The grocers in $\mathrm{KBH}$ who run small-scale businesses were categorised in the MC category. The older adults in $\mathrm{KBH}$ who were pensioners and housewives were categorised in the LC category. The interviews were conducted at their houses between 14 December and 22 December 2013.

Following Patton (2002), the data was analysed according to the following sequence. First, a brief note was written at the margin when reading the responses to form themes. Next, relevant responses were sustained and written on a paper in which questions that were asked during the interview had been written in advance. Then, similar responses given by the respondents were colour-coded. Finally, the responses that have been organized according to the same themes were transferred into a matrix form, as shown as in Table 1: Summary of the Respondents' Perceived Impacts of Tourism.

\section{Study Findings}

The findings in this research indicated that respondents in the three significantly different degrees of contact (HC, MC, and LC) have distinctive perceptions towards the social impacts of tourism in $\mathrm{KBH}$ (see Table $1-2$ and 3). Result indicated that the HC respondents perceived the homestay programme positively by listing several benefits from the programme. The MC respondents perceived more costs of tourism than the benefits. Similar to the HC respondents, the LC respondents were more positive with the homestay programme, although they did not participate in the programme.

\subsection{Local Residents’ Perceptions towards the Social Impacts of Tourism}

The HC respondents stated that the homestay programme has helped to increase their income. The respondents agreed that the programme has allowed them to run other businesses such as selling the handmade-handicraft products made from rattan, or vegetables and fruits harvested from their farm. One of the homestay operators further commented that "other 
businesses will come in like crafts, beads... and kayaking." Concerning positive impacts of tourism, the $\mathrm{HC}$ respondents acknowledged the job opportunities given to them. For the $\mathrm{MC}$ respondents, they perceived that the programme involves several benefits such as the opportunities to meet new people and increase in income, although it was not so obvious they were aware of the negative impacts. For example, conflicts between locals occurred when the grocers made an accusation towards the homestay operators for causing vandalism to the old Bidayuh traditional longhouse and the mini museum. Surprisingly, during the interview with one of the grocers, most of the grocers did not agree that they gain many profits from the homestay programme.

During the interview with one of the pensioners who was categorised in the LC category, he stated that the homestay programme has allowed the villagers to meet tourists who came to the village. The result indicated that the LC respondents acknowledged the arrival of tourists to the village. For LC category, by welcoming international tourists to the village has helped the villagers to get to know the lifestyles of the outsiders. Another LC respondent affirmed that the increasing number of tourist arrivals to the village has resulted in the "(constructing) a proper road to reach our village." The respondent further stated that the positive response from the tourists to come and visit the village has convinced the Government to give money to fund projects to improve public facilities in $\mathrm{KBH}$.

\subsection{Local Residents'Support for Additional Tourism Development or Support for Restrictions on Tourism Development}

In this research, respondents were also asked about the future of the homestay programme in $\mathrm{KBH}$. Based on their general responses to these questions, the $\mathrm{HC}, \mathrm{MC}$, and $\mathrm{LC}$ respondents had different perceptions towards their support for additional tourism development or support for restrictions on tourism development (see Table 1-4, 5 and 6). From the findings, the $\mathrm{HC}$ respondents and $\mathrm{MC}$ respondents showed great support for additional tourism development in $\mathrm{KBH}$, while the LC respondents have both support for additional tourism development as well as support for restrictions on tourism development. Concerning the support for additional tourism development, several responses were examined between the $\mathrm{HC}$ respondents and MC respondents. The responses by the HC respondents indicated that they appreciated the effort shown by the Government to distribute the benefits from the homestay programme equally to every members of the local community in $\mathrm{KBH}$. 
Table 1. Summary of the respondents' perceived impacts of tourism

\begin{tabular}{|c|c|c|c|c|}
\hline No & Aspects & & & \\
\hline & Degree of contact & $\begin{array}{l}\text { High } \\
\text { contact }\end{array}$ & $\begin{array}{l}\text { Medium } \\
\text { contact }\end{array}$ & Low contact \\
\hline 1 & Communicate with Tourists & Very often & Sometimes & Not that often \\
\hline 2 & Social Benefits & Yes & No & Yes \\
\hline 3 & Social Costs & No & Yes & No \\
\hline 4 & $\begin{array}{l}\text { Support for Additional } \\
\text { Tourism Development }\end{array}$ & Yes & Yes & Yes \\
\hline 5 & $\begin{array}{l}\text { Support for Restrictions on } \\
\text { Tourism Development }\end{array}$ & No & No & $\begin{array}{l}\text { Some respondents, but } \\
\text { not all }\end{array}$ \\
\hline 6 & $\begin{array}{l}\text { Future Tourism } \\
\text { Development }\end{array}$ & Positive & Positive & Positive \\
\hline
\end{tabular}

Source: Researcher's fieldwork (2013)

Compared with the $\mathrm{HC}$ respondents and $\mathrm{MC}$ respondents, the $\mathrm{LC}$ respondents were both supportive for additional tourism development as well as supportive for restrictions on tourism development. Their support for the tourism development can be associated with the high hopes for the homestay programme committee to organize more attractive activities that not only encourage the villagers to participate in the activities, but also to allure more tourists to come into the village. However, one respondent in the LC category stated her unwillingness to communicate with international tourists due to her inability to understand the English language. This same respondent concluded her response by mentioning her disagreement for the homestay programme in $\mathrm{KBH}$ to continue to develop in the future. Such a result was not surprising since the LC respondents were also supportive for restrictions on tourism development in $\mathrm{KBH}$. It is understandable that low contact and infrequent communication with tourists resulted in negative perceptions towards the impacts brought about by the homestay programme.

\section{Discussions and Conclusions}

Earlier, it has been mentioned in the Introduction part that two frameworks, namely 1) Social Exchange Theory by Ap (1992); and 2) Model of Resident Tourism Perceptions and Attitudes by Perdue et al., (1990) were adapted in this research. These two frameworks were combined to construct a conceptual framework resulting from the findings in this research. This research has revealed that when it comes to the theory as a theoretical basis for this research, the explanation given was not as straightforward as provided by SET and Model of Resident Tourism Perceptions and Attitudes. Having mentioned these two models, the models have failed to consider the heterogeneity aspect when it comes to explanation of the variety of perceptions towards tourism impacts from the local residents.

Concerning the SET, Zhou et al., (2013) investigated whether SET is suitable to be adapted to explain the benefits or costs perceived by the local residents that influenced their positive or 
negative perceptions towards tourism impacts. The SET has limited its explanations on the local residents' perceptions towards tourism impacts. SET was also being criticized for not being able to explain the situation where the local residents were still supporting the future tourism development despite not receiving any benefits from tourism activity. Therefore, this study proposes a more complex framework that has acknowledged the homogeneity aspect for the study of locals' perceptions towards tourism impacts. The combination of these two frameworks provides an adequate explanation of variety in perceptions towards tourism impacts from local residents that influenced by their different degrees of contact with tourists in KBH (see Figure 1).

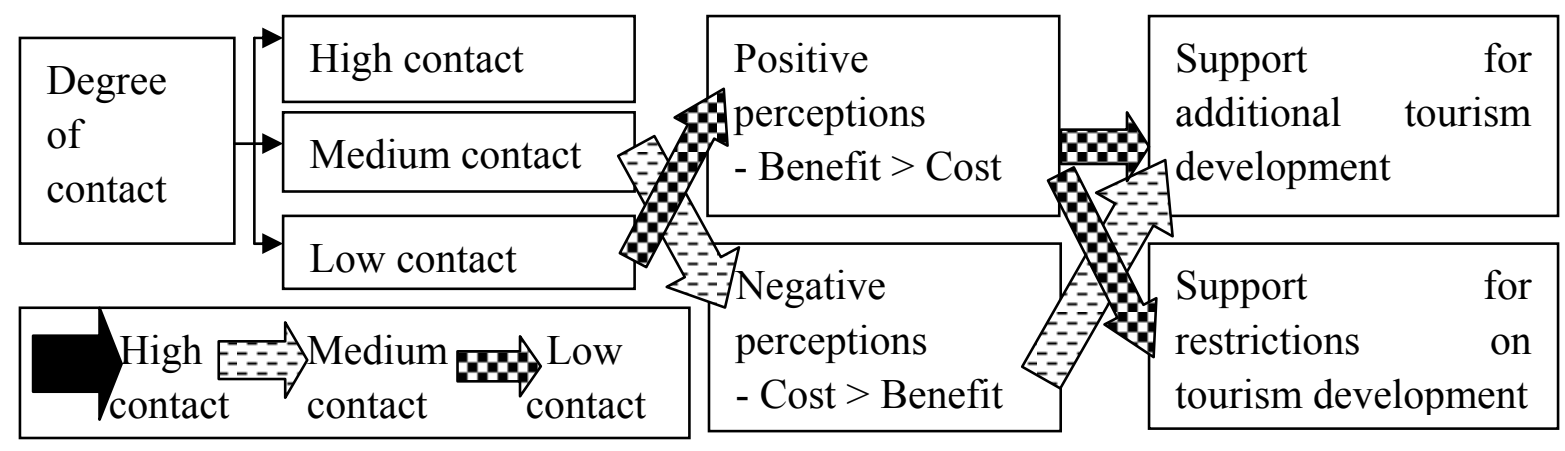

Figure 1. Conceptual Framework for Local Residents' Perceptions towards Tourism Impacts

\section{Based on Different Degrees of Contact in KBH}

As shown in Figure 1, it was apparent that the HC respondents who had frequent contact with tourists compared to the other groups of respondents, did not perceive the homestay programme negatively. The results indicated that the local residents who were involved in the homestay programme support for additional tourism development. Compared with the $\mathrm{HC}$ respondents, the $\mathrm{MC}$ respondents were negative with the homestay programme in $\mathrm{KBH}$. Although the MC respondents showed negative response towards the programme, they showed their support for additional tourism development. It is worth mentioning that the LC respondents seemed to both support for additional tourism development and support for restrictions on tourism development. Thus, this research provides evidence for the argument by Brunt and Courtney (1999) that the local people are not a homogeneous group, particularly when the study involves locals' perceptions towards impacts of tourism.

The three different groups of respondents in this research, namely 1) High Contact; 2) Medium Contact; and 3) Low Contact category have revealed different perceptions towards social impacts of tourism. For HC respondents, understanding their perceptions towards social impacts and later their support for additional tourism development has clearly indicated that the homestay programme in $\mathrm{KBH}$ is toward the positive future. For MC respondents, they have more negative points when asked about the social impacts of tourism in the village. Nevertheless, the MC respondents were seen to be supportive for additional tourism development, similar with the HC respondents. The results from the interviews with the $\mathrm{MC}$ respondents were supported by finding from a previous study by Horn et al., (2000). In their study, local people were positive towards the future tourism development although tourism has impacted them negatively. Such results explained the reasons why this research 
involves more than one group of local residents to understand the variety of perceptions resulted from the homestay programme.

While the first two local resident groups had different perceptions of the social impacts of tourism resulted from the homestay programme, they showed support for additional tourism development in the village. The findings from this research are consistent with a recent study done by Zhou et al., (2013), which revealed that two different group of respondents (Ambivalents and Rationalists) pointed out several benefits and costs of the gaming tourism development in Macau, yet were supportive of the industry development. Compared with the $\mathrm{HC}$ and $\mathrm{MC}$ respondents, the LC respondents were slightly disagreed for the homestay programme to continue in the future. Findings of this research provide evidence for the argument by Brunt and Courtney (1999) that local residents with no contact at all with tourists, which also means seeing the tourists from a distance, showed both approvals and rejections at the same time, although it was obvious that the LC respondents perceived benefit more than the costs received by the local people.

Findings from this research also provide important practical and theoretical implications. The findings of the perceived social impacts by the residents are useful for the local government to have a plan for future activities relating to the homestay programme. The committee members of $\mathrm{KBH}$ could help to increase the economic opportunities for the grocers at the village. For example, grocers can take turns to become the suppliers of mineral water or carbonated drinks for tourists during the homestay event in the village. To encourage the villagers to directly and indirectly involve as the decision makers in the village, a number of meetings can be held from time to time by inviting the whole community members of various backgrounds and interests. Such meetings can be the channel of communication between the committee members of $\mathrm{KBH}$ and the entire community to bring up issues related to the homestay programme. For the welfare of the villagers, both suggestions and problems could be brought up during the meeting. The theoretical contribution in this research to the existing body of knowledge in the literature is the different degrees of contact between local people and tourists in a tourist destination. By having these three elements, namely, 1) high contact; 2) medium contact; and 3) low contact, the impacts as perceived by the local people could be varied and detailed in a sense that not every individual in the community has the same perception towards tourism and its impacts.

Therefore, this research concluded that degree of contact has a role in determining the local perceptions of social impacts of homestay programme in $\mathrm{KBH}$. All of these three groups of respondents had different perceptions towards social impacts resulting from the homestay programme. It was also found that the LC respondents were not necessarily supported additional tourism development, although several benefits from the homestay programme were mentioned during the interviews. By acknowledging the heterogeneity of the local residents in terms of perceiving the tourism impacts, a lot more conflicts and issues faced by these groups of respondent can be identified. The limitation of this research should also be pointed out. Although by employing interview to obtain richer findings resulted in different perceptions towards tourism impacts, the responses particularly from the older adults in the LC category were almost not relevant or helpful during analysing the data. Thus, a construction of a simpler way in asking questions is recommended for future research. 
To conclude, research on local perceptions should not only involve those who receive benefit from tourism activity, but also other community members. The findings indicated the need for further research to enhance the knowledge about perceived tourism impacts from several different groups of local residents. Lastly, this research has explained the variety in perceptions towards the homestay programme as well as the future development in KBH by acknowledging the heterogeneity of the local residents who lived in a small community in Kuching, Sarawak.

\section{References}

Abdul Razzaq, A. R., Hadi, M.Y., Mustafa, M.Z., Hamzah, A., Khalifah, Z., \& Mohamad, N.H. (2011). Local community participation in homestay program development in Malaysia. Journal of Modern Accounting and Auditing, 7(12), 1418-1429.

Ap, J. (1992). Residents' perceptions on tourism impacts. Annals of Tourism Research, 19(4), 665-690. http://dx.doi.org/10.1016/0160-7383(92)90060-3

Bhuiyan, M.A.H., Siwar, C., \& Mohamad Ismail, S. (2013). Socio-economic impacts of home stay accommodations in Malaysia: A study on home stay operators in Terengganu State. Asian Social Science, 9(3), 42-49. http://dx.doi.org/10.5539/ass.v9n3p42

Brunt, P., \& Courtney, P. (1999). Host perceptions of socio-cultural impacts. Annals of Tourism Research, 26(3), 493-515. http://dx.doi.org/10.1016/S0160-7383(99)00003-1

Horn, C., Simmons, D.G., \& Fairweather, J.R. (2000). Evolving community response to tourism and change in Rotorua. [Online] Available: http://www.researcharchive.lincoln.ac.nz/bitsream/10182/118/4/TREC_Report_14.pdf (November 11, 2014)

Hsu, C.H. (2006). Tao residents' perceptions of social and cultural impacts of tourism in Lan-Yu, Taiwan. (Master dissertation). Retrieved from ProQuest Digital Dissertations. (AAT 1439247).

Long, P.H. (2012). Tourism impacts and supports for tourism development in Ha Long Bay, Vietnam: An examination of residents' perceptions. Asian Social Science, 8(8), 28-39.

Ministry of Tourism and Culture, Malaysia (MOTAC). (2014). Garis panduan pendaftaran homestay [The homestay registration guidelines]. [Online] Available: http://www.motour.gov.my/en/download/viewcategory/2-homestay (November 26, 2014)

Patton, M.Q. (2002). Qualitative research and evaluation methods (3rd ed.). Thousand Oaks: Sage Publications.

Perdue, R.R, Long, P.T, \& Allen, L.R (1990). Resident support for tourism development. Annals of Tourism Research, 586-599. http://dx.doi.org/10.1016/0160-7383(90)90029-Q 


\section{Macrothink}

Journal of Management Research

ISSN 1941-899X 2015, Vol. 7, No. 2

Zhou, Y., Lu, Y., \& Yoo, J.E. (2013). Residents' perceived impacts of gaming development in Macau: Social representation perspectives. Asia Pacific Journal of Tourism Research, 19(4-6), 579-599.

\section{Copyright Disclaimer}

Copyright for this article is retained by the author(s), with first publication rights granted to the journal.

This is an open-access article distributed under the terms and conditions of the Creative Commons Attribution license (http://creativecommons.org/licenses/by/3.0/). 